\title{
Aneuploidy and Epithelial Cancers: The Impact of Aneuploidy on the Genesis, Progression and Prognosis of Colorectal and Breast Carcinomas
}

\author{
Jens K. Habermann ${ }^{1}$, Gert Auer², Madhvi Upender 3 , Timo Gemoll1, \\ Hans-Peter Bruch ${ }^{1}$, Hans Jörnvall ${ }^{2}$, Uwe J. Roblick ${ }^{1}$ and Thomas Ried ${ }^{3}$ \\ ${ }^{1}$ University of Lübeck \\ ${ }^{2}$ Karolinska Institute \\ ${ }^{3}$ National Cancer Institute \\ ${ }^{1}$ Germany \\ ${ }^{2}$ Sweden \\ ${ }^{3}$ USA
}

\section{Introduction}

Aneuploidy is a defining feature of epithelial cancers with an impact on the genesis, progression and prognosis of these malignancies. Essentially all sporadic, mismatch repair proficient colorectal carcinomas are defined by a non-random distribution of genomic imbalances. Regarding breast cancer, however, aneuploid and near diploid cases show almost similar frequencies. Independent of the tumor entity, increased levels of aneuploidy result in a worse clinical outcome. For breast and colorectal carcinomas, aneuploidy has been reported as an independent prognostic factor with an impact comparable to that of the tumor stage. Unfortunately, the translation of this knowledge into the clinic was slow. Prognostication in breast cancer is augmented by gene expression profiles of poor or good prognosis. Interestingly, there is growing evidence that prognostic gene expression signatures simply reflect the degree of genomic instability. This is not surprising since gross nuclear aneuploidy is reflected in a strikingly recurrent and tumor entity specific distribution of chromosomal imbalances. Chromosomal imbalances, in turn, do significantly modulate resident gene expression levels. Furthermore, aneuploidy also affects protein expression. Proteomics has therefore become a powerful tool to unravel potential new targets for diagnostics, prognostication and therapeutic stratification. There is also increasing evidence that aneuploidy precedes invasive disease and can already be detected in premalignant lesions such as colon adenomas and/or ulcerative colitis. It is therefore reasonable to assume that aneuploidy plays a crucial role during carcinogenesis, an interpretation consistent with its direct influence on disease outcome. This has triggered considerable efforts to elucidate how aneuploidy develops and what its impact is on the genetic equilibrium of cells at the molecular level. 


\section{Nuclear DNA content, genomic instability and chromosomal aneuploidy}

In 1914, Theodor Boveri proposed that the loss or gain of "inhibiting" or "promoting" chromosomes, respectively, might cause uncontrolled cell proliferation (Boveri 1914; Ried 2009). This hypothesis could only be validated after technical progress allowed a more detailed analysis of the human genome and after the correct number of human chromosomes was established to be 46 (Tjio and Levan 1956). Each chromosome consists of two chromatids that are joined at the centromere. The centromeric region is important for the attachment of kinetochores that are responsible for the segregation of the chromatids during mitotic cell division, a central feature for maintaining genomic stability (Kops, Weaver, and Cleveland 2005). Chromosomes can be classified by their centromere position, size and banding pattern (Strachan and Read 1999). Telomeres are located at the ends of chromosomes to protect the integrity of the chromosomal DNA. They harbour proteins that protect the ends of chromosomes from, e.g., recombination, nuclease attacks, and end-to-end fusions. The DNA polymerase telomerase is responsible for the maintenance of the telomere length that physiologically becomes shorter with each cell division. Telomerase reactivation has been identified as an important mechanism for malignant transformation (Shay and Wright 2002). Both abnormalities of centromere and telomere function can lead to aneuploidy.

\subsection{Clonal expansion and proliferation}

Boveri's hypothesis that chromosomal aberrations might cause uncontrolled cell proliferation was first supported by the detection of the Philadelphia chromosome in 1960. The Philadelphia chromosome shows a translocation, $t(9 ; 22)$, characteristic for chronic myelogenous leukemia (Rowley 1973). This translocation causes synthesis of a fusion protein with increased tyrosine kinase activity (p210) that increases cell proliferation. Translocations belong to those mutations that affect the chromosomal structure. Inversions, deletions and duplications are also referred to as structural aberrations. Such cancer promoting chromosomal aberrations can affect different genes, causing either a gain of function (proto-oncogenes) or a loss of function (tumor suppressor genes). Whereas mutations in oncogenes are mainly dominant, mutations in tumor suppressor genes are typically recessive and follow Knudson's two-hit model: The first mutation "hits" one allele of a tumor suppressor gene. The presence of the remaining wild-type allele preserves the tumor inhibiting function. The second "hit" mutates the remaining wild-type allele, which results in the complete loss of gene function (Knudson 1979). In addition to structural chromosomal aberrations, we also observe alterations of chromosome number, i.e., aneuploidy (Giaretti et al. 2004). While one reason for the emergence of structural chromosomal aberrations are deficiencies in the repair of DNA double strand breaks (Sinicrope, Rego, Foster, et al. 2006), there is mounting evidence that numeric chromosome imbalances are caused by chromatid segregation errors during mitotic cell division (D'Amours and Jackson 2002; Jallepalli and Lengauer 2001; Loeb and Loeb 2000; Vessey, Norbury, and Hickson 1999). Loss of bub1, for instance, a gene involved in the mitotic checkpoint, increases chromosome segregation errors (Cahill et al. 1998). Alternatively, overexpression of cyclin E, a cell cycle regulator results in centrosome amplification (Nigg 1996), and has been observed in a variety of malignancies causing chromosome instability and aneuploidy (Spruck, Won, and Reed 1999; Donnellan and Chetty 1999). The completion 
of the cell and DNA replication cycle requires the coordination of a variety of macromolecular syntheses, assemblies and movements. These complex processes are normally tightly controlled by regulatory pathways or checkpoints in order to maintain genomic stability. However, cancer cells often exhibit mutations that allow bypassing those regulatory mechanisms leading to aberrant growth and clonal expansion. Gain-of-function of growth factor receptors, often through an increase in copy number, is also frequently observed in tumors (Scharf and Braulke 2003).

\subsection{Cell cycle regulation}

Cell cycle regulators, namely cyclin-dependent kinases (cdks) and their regulatory subunits (cyclins), are driving forces of the cell cycle and act at different cellular checkpoints. In 1951, Howard and Pelc divided the cell cycle into four phases (GAP1, synthetic phase, GAP2, and mitosis) (Howard and Pelc 1951). Later on, abbreviations were used that described the preceding phase as G1, the synthetic phase as S phase, the phase before cell division as G2, and the mitosis phase as M phase (Zetterberg, Larsson, and Wiman 1995). Since the genetic material is duplicated in the $S$ phase and divided in the $\mathrm{M}$ phase, the transition of a cell into these two phases is crucial and regulated by the G1/S checkpoint and the G2/M DNA damage checkpoint. The cascade of interacting cyclins and cdks during the cell cycle can be briefly summarized as follows: The activation of cdk4 and cdk6 by cyclin D leads the cell from the middle of G1 to the G1/S checkpoint. Active cyclin E/cdk2 complexes then trigger the transition from $\mathrm{G} 1$ to $\mathrm{S}$ phase. The cyclin A/cdk2 complex promotes the cell cycle progress from the G1/S checkpoint into G2 (Sherr 1993). Cyclin A can therefore serve as a proliferation marker for committed cells that will pass through the S and G2 phase (Zindy et al. 1992). Cyclin A also binds cdk1 from the end of $S$ to the beginning of the $M$ phase. Its function has not been conclusively elucidated but aberrant expression of cyclin A/cdk1 complexes has been associated with tumorigenesis (Liao et al. 2004). In addition, cyclin A overexpression itself significantly reflects poor prognosis of carcinoma patients (Handa et al. 1999). For the transition from $G 2$ into $M$ phase, cyclin $B$ activates cdk1. In addition to the cell cycle regulation by cdks and their cyclins, other regulatory factors have been described such as the transcription factor TP53 which is responsible for leading the cell into G1 and G2 arrest (Vousden 2002). Another checkpoint has been described for the $M$ phase which has been subdivided into five phases that harbour specific stages of the mitotic cell division: prophase, prometaphase, metaphase, anaphase, and telophase. The appropriate transition from prometaphase and metaphase to anaphase is highly important to guarantee genomic stability. The cellular mechanism that could be used to delay prometaphase or metaphase in response to spindle defects or impaired chromosome segregation has been termed the spindle integrity checkpoint (Allshire 1997).

\section{Aneuploidy and epithelial malignancies}

Aneuploidy is a characteristic genetic alteration of the cancer genome (Duesberg et al. 1998; Lengauer, Kinzler, and Vogelstein 1998; Ried et al. 1999). When the first quantitative measurements of the DNA content were applied to cancer cells, aneuploidy was defined as a variation in the nuclear DNA content of cancer cells within a tumor (Caspersson 1979). In addition to nuclear aneuploidy, an increased resolution of cytogenetic techniques such as chromosome banding, comparative genomic hybridization (CGH), spectral karyotyping 
(SKY), and multicolor fluorescence in situ hybridization allowed the detection of specific nonrandom imbalances, heretofore referred to as chromosomal aneuploidy (Caspersson et al. 1970; Kallioniemi et al. 1992; Schrock et al. 1996; Speicher, Gwyn Ballard, and Ward 1996). Indeed, despite genetic instability in cancer genomes, cancer cell populations as a whole display a surprisingly conserved, malignancy-specific pattern of genomic imbalances (Ried et al. 1999; Knuutila et al. 1998; Forozan et al. 1997). Interestingly, chromosomal aneuploidy can be the first detectable genetic aberration found during human tumorigenesis, e.g., in preinvasive dysplastic lesions (Hittelman 2001; Hopman et al. 1988; Heselmeyer et al. 1996; Solinas-Toldo et al. 1996). This suggests both an initial requirement for the acquisition of specific chromosomal aneuploidy and a requirement for the maintenance of these imbalances despite genomic and chromosomal instability. This would be consistent with continuous selective pressure to retain a specific pattern of chromosomal copy number changes in the majority of tumor cells (Bomme et al. 1994; Ried et al. 1999; Nowak et al. 2002; Desper et al. 2000). Chromosomal aneuploidy is also the earliest detectable genomic aberration in cell culture model systems in which cells are exposed to carcinogens or subject to spontaneous transformation (Barrett et al. 1985; Padilla-Nash et al. 2011). The conservation of these specific patterns of chromosomal aneuploidy indicates a fundamental biological role in tumorigenesis.

\subsection{Aneuploidy and colorectal cancer}

\subsubsection{Chromosomal aneuploidy in sporadic colorectal cancer (SCC)}

Malignant transformation of the colorectum is defined by the sequential acquisition of genetic alterations, both at gene-specific and on chromosomal levels (Fearon and Vogelstein 1990). Many of these aberrations can be visualized as specific chromosomal gains and losses resulting in a conserved and malignancy-specific pattern of genomic imbalances (Ried et al. 1996). One of the earliest acquired genetic abnormalities during colorectal tumorigenesis are copy number gains of chromosome 7 (Bomme et al. 1994) which can already be observed in benign polyps. At later stages, e.g., in high-grade adenomas or in invasive carcinomas, additional numeric aberrations such as gains of chromosomes and chromosome arms 8q, 13, and $20 q$, and losses that map to $8 p, 17 p$, and $18 q$ become prominent (Figure 1). For a comprehensive summary see the "Mitelman Database of Chromosome Aberrations in Cancer" at http://cgap.nci.nih.gov/Chromosomes/Mitelman. Chromosomal aneuploidy is accompanied by specific mutations in tumor suppressor genes and oncogenes, including e.g., APC and TP53 (Vogelstein and Kinzler 2004). It is therefore well accepted that both chromosomal aneuploidy and specific gene mutations, are required for tumorigenesis.

\subsubsection{Chromosomal aneuploidy and ulcerative colitis-associated colorectal cancer (UCC)}

Unlike sporadic colorectal tumors, UCCs do not follow the adenoma-carcinoma sequence, and their sequential acquisition of chromosomal aneuploidy and gene mutations is less well established. It was therefore questioned if the pattern of chromosomal alterations in UCC is similar to that known for sporadic carcinomas. Earlier reports suggested that genomic imbalances observed in UCC cluster on the same chromosomes as those observed in sporadic colorectal carcinomas (Kern et al. 1994; Holzmann et al. 2001; Willenbucher et al. 1997; Loeb and Loeb 1999; Aust et al. 2000). 


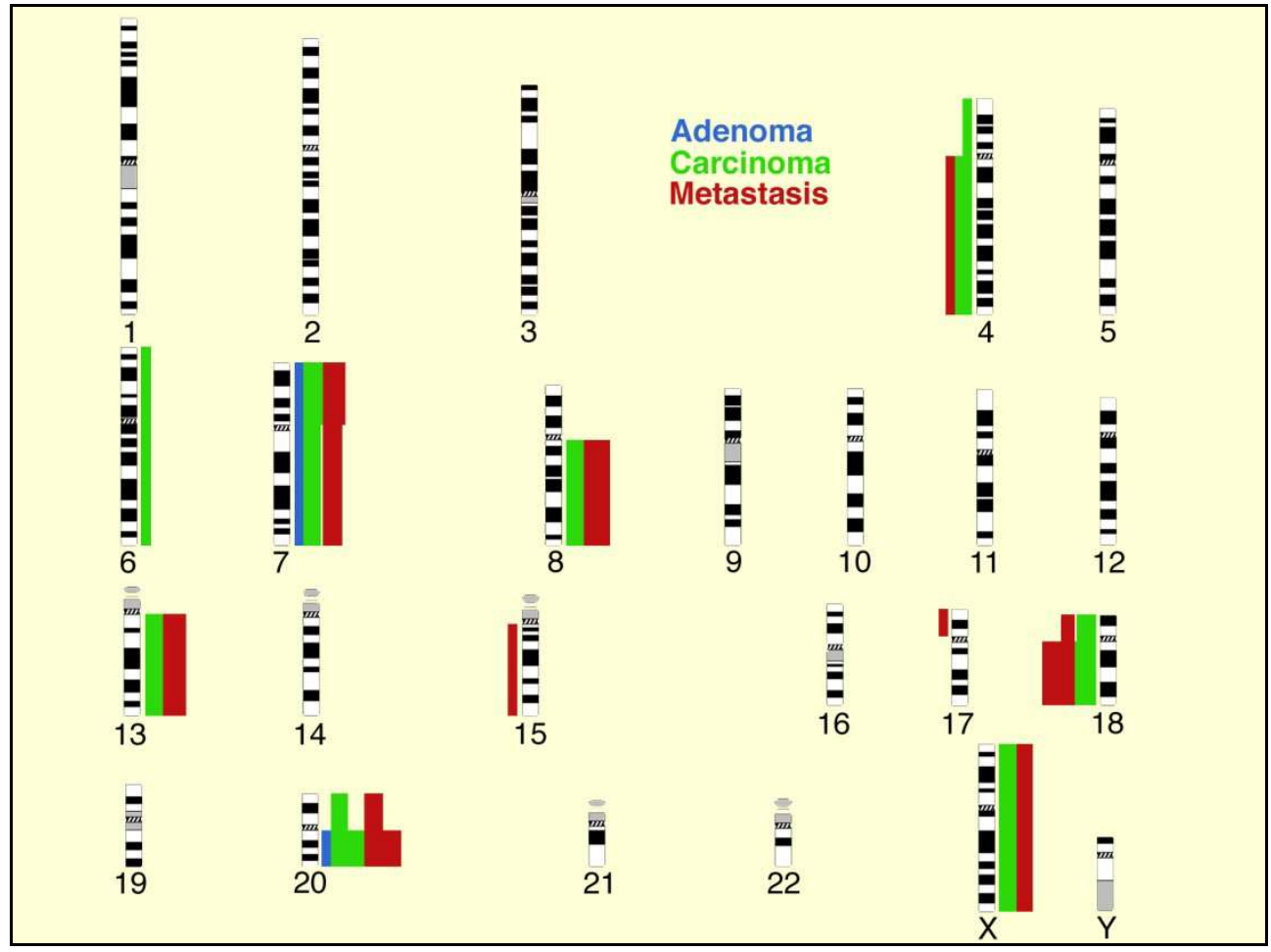

Fig. 1. Comparison of genomic imbalances in sporadic adenomas $(n=14)$, sporadic colorectal carcinomas $(n=15)$, and liver metastasis of sporadic colorectal carcinomas $(n=12)$. Bars on the left side of the chromosome ideogram denote a loss of sequence in the tumor genome, bars on the right side a gain of sequence in the tumor genome. The number of alterations per chromosome is normalized to 10 cases for each disease stage. Only ratios greater than 2 have been considered. Figure modified from (Habermann et al. 2007).

The analysis by Habermann and colleagues comprised the largest sample collection of UCCs from one clinical center and supports these findings: all 19 UCC specimens showed chromosomal imbalances by comparative genomic hybridization (CGH) (Habermann et al. 2003) that mainly cluster on the same chromosomes as described for sporadic colorectal cancer (Figure 1). These data clearly indicate that the tumor cell population as an entity of UCCs selects for a distribution of genomic imbalances that is similar to sporadic carcinomas. It therefore seems logic to conclude that the tissue origin of the tumor cell and not the mode of tumor induction defines the similarity between sporadic colorectal cancers and UCC. This is in striking contrast to hereditary colorectal carcinomas arising in the background of mismatch repair deficiency, where neither aneuploidy nor specific chromosomal imbalances are observed (Ghadimi et al. 2000; Schlegel et al. 1995). 


\subsubsection{Nuclear aneuploidy and prognosis of colorectal cancer (SCC and UCC)}

The strikingly conserved pattern of chromosomal aneuploidy in sporadic and ulcerative colitis-associated colorectal carcinomas can be reflected by nuclear DNA aneuploidy. Hereby, flow and/or image cytometry are reliable tools with excellent clinical applicability also for high-throughput clinical diagnostics. Interestingly, reported frequencies of aneuploidy in UCCs vary inconsistently between 28.6\% and 100\% (Holzmann et al. 1998; Fozard et al. 1986). One limitation of former studies might be the overall low number of UCC cases analyzed, varying from single case studies up to 17 UCC patients (Clausen et al. 2001; Makiyama et al. 1995; Burmer, Rabinovitch, and Loeb 1991). Against this background, we had recently compiled a single center cohort comprising 31 UCCs that were assessed for the frequency of nuclear aneuploidy and its association to clinical parameters and survival and in comparison to 257 sporadic colorectal carcinomas (Gerling et al. 2010). Ploidy measurements were performed by means of image cytometry which allows the simultaneous assessment of histomorphology. Histograms were classified according to Auer (Figure 2) (Auer, Caspersson, and Wallgren 1980).

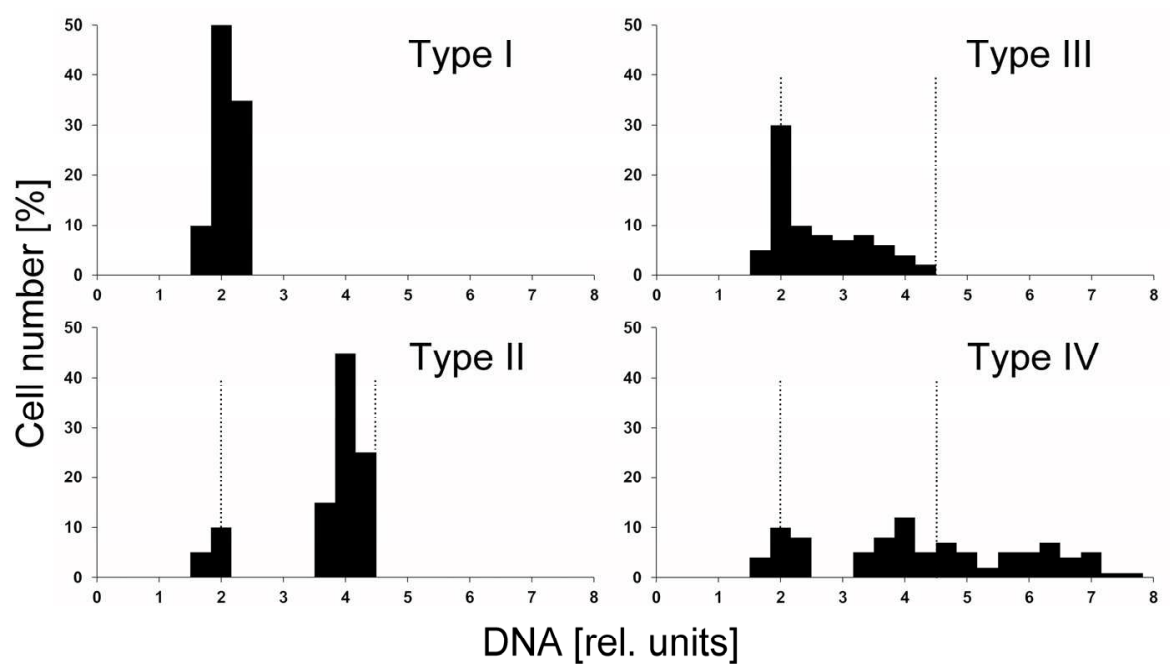

Fig. 2. DNA Histogram types according to Auer (Auer, Caspersson, and Wallgren 1980). Histograms characterized by a single peak in the diploid or near-diploid region (1.5-2.5 c) were classified as type I. The total number of cells with DNA values exceeding the diploid region $(>2.5 \mathrm{c}$ ) was $<10 \%$. Type II histograms showed a single peak in the tetraploid region (3.5- $4.5 \mathrm{c})$ or peaks in both the diploid and tetraploid regions ( $>90 \%$ of the total cell population). The number of cells with DNA values between the diploid and tetraploid region and those exceeding the tetraploid region ( $>4.5 \mathrm{c}$ ) was $<10 \%$. Type III histograms represented highly proliferating near-diploid cell populations and were characterized by DNA values ranging between the diploid and the tetraploid regions. Only a few cells $(<5 \%)$ showed more than $4.5 \mathrm{c}$. The DNA histograms of types I, II, and III thus characterize euploid cell populations. Type IV histograms showed increased $(>5 \%)$ and/or distinctly scattered DNA values exceeding the tetraploid region $(>4.5 \mathrm{c})$. These histograms reflect aneuploid populations of colon mucosa nuclei with decreased genomic stability. 
Interestingly, UCCs showed aneuploidy at a significantly higher frequency than sporadic colorectal carcinomas (100\% versus $74.6 \%$; $P<0.0006)$ (Gerling et al. 2010). A logistic regression analysis assessed age, sex, UICC stage, T- and N-status, histologic tumor grading, underlying inflammation, and DNA ploidy status. Out of these features, only age and DNA ploidy status were significant parameters indicating both patients of higher age at diagnosis and patients with aneuploid malignancy have a poor survival prognosis. Additional logistic regression analysis comprising these two significant parameters only confirmed age (odds ratio $[\mathrm{OR}], 1.05 ; 95 \% \mathrm{CI}, 1.02-1.09 ; P=0.003)$ and DNA ploidy $(\mathrm{OR}, 4.07$; 95\% CI, $1.46-11.36$; $P=0.007)$ to be independent prognostic parameters. Among those, DNA aneuploidy with an OR of 4.07 seemed to be the strongest independent prognostic marker for R0-resected colorectal cancer patients overall. The dominance of aneuploidy as an independent prognostic factor in patients with SCC and UCC was further supported by the fact, that patients with diploid tumors at advanced stages (UICC stage III/IV) did present a survival comparable to that of patients with aneuploid tumors at early stages (Figure 3). The latter finding might even suggest that the presence of aneuploid tumor cell populations may influence the patient's prognosis more dominantly than tumor stage.

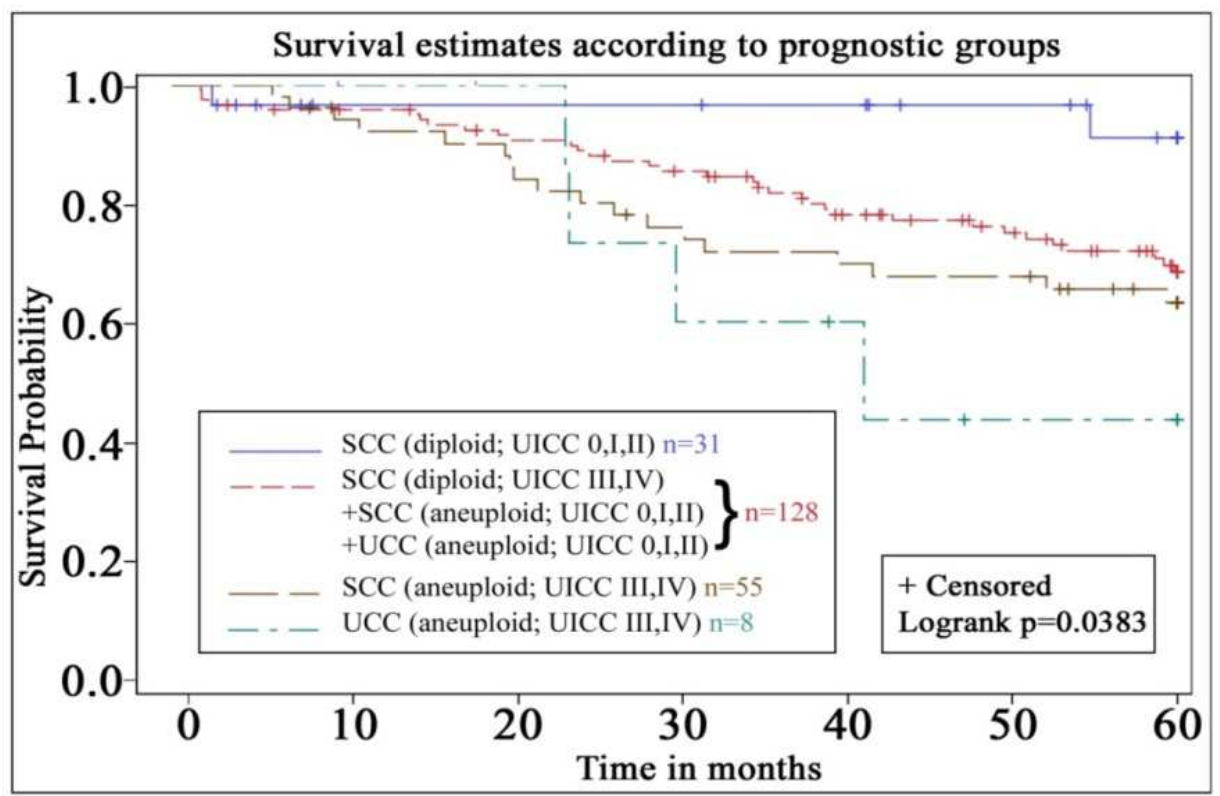

Fig. 3. Kaplan-Meier survival estimates of significant prognostic groups according to UICC stage, ploidy status, and underlying inflammatory disease. SCC, sporadic colorectal cancer; UCC, ulcerative colitis-associated colorectal cancer. Modified from (Gerling et al. 2010).

\subsubsection{Nuclear aneuploidy and cancer risk assessment in ulcerative colitis and sporadic colon adenomas}

The higher frequency of nuclear aneuploidy in UCCs than in sporadic colorectal cancer might indicate the dominance of genomic instability not only at the time when malignancy 
is overt but also for the development of malignant properties. In order to evaluate aneuploidy as a potential predictive marker in patient risk assessment, two groups were analyzed (Habermann et al. 2001): eight patients with UCC and 16 ulcerative colitis (UC) patients without malignancy but comparable risk factors according to the duration of disease, extent of inflammation and occurrence of epithelial dysplasia. A total of 683 paraffin-embedded mucosal biopsies were evaluated for inflammatory activity, grade of dysplasia and ploidy status. In all biopsies, mild or moderate inflammatory activity was present in $78 \%$ while low-grade or high-grade dysplasia was found in $5.5 \%$ overall. No difference in inflammatory activity and dysplasia between patient groups could be detected (Habermann et al. 2001). One of the most important findings of this study was the detection of highly aneuploid epithelial cell populations scattered over the colon and rectum in premalignant biopsies of all eight UCC patients. These lesions could be observed up to 11 years prior to the final cancer diagnosis (average 7.8 years). Aneuploidy was found in macro- and microscopically unsuspicious mucosa, could even be detected in regenerative epithelium, and was not related to dysplasia. DNA aneuploidy occurred more frequently in biopsies $(75 \%)$ of ulcerative colitis patients with a subsequent UCC than in those without subsequent malignancy $(14 \%, p=0.006)$. All eight UCC specimens themselves also showed aneuploidy. In line with these findings, Löfberg et al. reported aneuploid biopsies in $25 \%$ of high-risk patients at least once during 10 years of observation (Lofberg et al. 1992). In other studies, aneuploidy has been repeatedly observed also in non-dysplastic mucosa of highrisk patients (Rubin et al. 1992). It seems therefore reasonable to suggest that genomic instability, represented by DNA aneuploidy, might initiate malignant transformation in colitis as an early event. However, aneuploidy may be reversible over time once cells are no longer exposed to the inducing carcinogen (Auer et al. 1982; Ono et al. 1984). Thus, nuclear aneuploidy might need to be followed by multiple cellular alterations in order to reach malignant properties.

In sporadic colorectal carcinogenesis, adenomas are considered premalignant lesions. However, individual colorectal adenomas have different propensities to progress to malignancy. We therefore explored whether these differences could be explained by chromosomal aberrations, oncogene amplifications, and/or deletions of tumor-suppressor genes. Fluorescence in situ hybridization (FISH) with gene specific probe sets was applied to 18 adenomas of patients without synchronous or subsequent carcinoma, 23 adenomas of carcinoma patients, and 6 matched carcinomas (Habermann et al. 2011). The probe sets included centromere probes for chromosomes 17 and 18 (CEP17 and CEP18), as well as gene-specific probes for SMAD7 (18q21.1), EGFR (7p12), NCOA3 (20q12), TP53 (17p13.1), $M Y C$ (8q24.21), and RAB20 (13q34).

First, gene copy numbers were correlated with the DNA ploidy status independent of patient groups: EGFR amplifications correlated with SMAD7 deletions $(\mathrm{P}<0.01)$ and an increased DNA stem line value $(\mathrm{P}=0.019)$. NCOA3 amplifications were more frequently observed in aneuploid adenomas and increasing NCOA3 gene copy number signals correlated with higher DNA stem line values $(P=0.023$, Figure 4$)$. A deletion of TP53 was more frequently observed in aneuploid adenoma samples $(\mathrm{P}=0.029)$. MYC amplifications were more frequently observed in adenoma samples with increased DNA stem line values $(\mathrm{P}<0.01)$ and in adenoma samples that were assessed to be aneuploid $(\mathrm{P}=0.029)$. RAB20 amplifications also correlated with increased DNA stem line values $(P<0.05)$. 
Second, comparing adenomas with and without synchronous carcinomas showed that a higher genomic instability index of CEP18, SMAD7, and EGFR (the genomic instability index was measured by dividing the number of different signal patterns by the number of analyzed cells) could be detected in the adenoma samples of patients with carcinoma than in adenoma samples of patients without synchronous or subsequent carcinoma $(P=0.037)$. Furthermore, TP53 deletions were more frequently observed in adenoma samples of patients with synchronous carcinoma $(\mathrm{P}=0.045)$.

Third, evaluation of the prognostic potential for adenoma recurrence revealed that a diploid signal count for NCOA3 was associated with a longer adenoma recurrence-free observation time $(\mathrm{P}=0.042$, Figure 4).
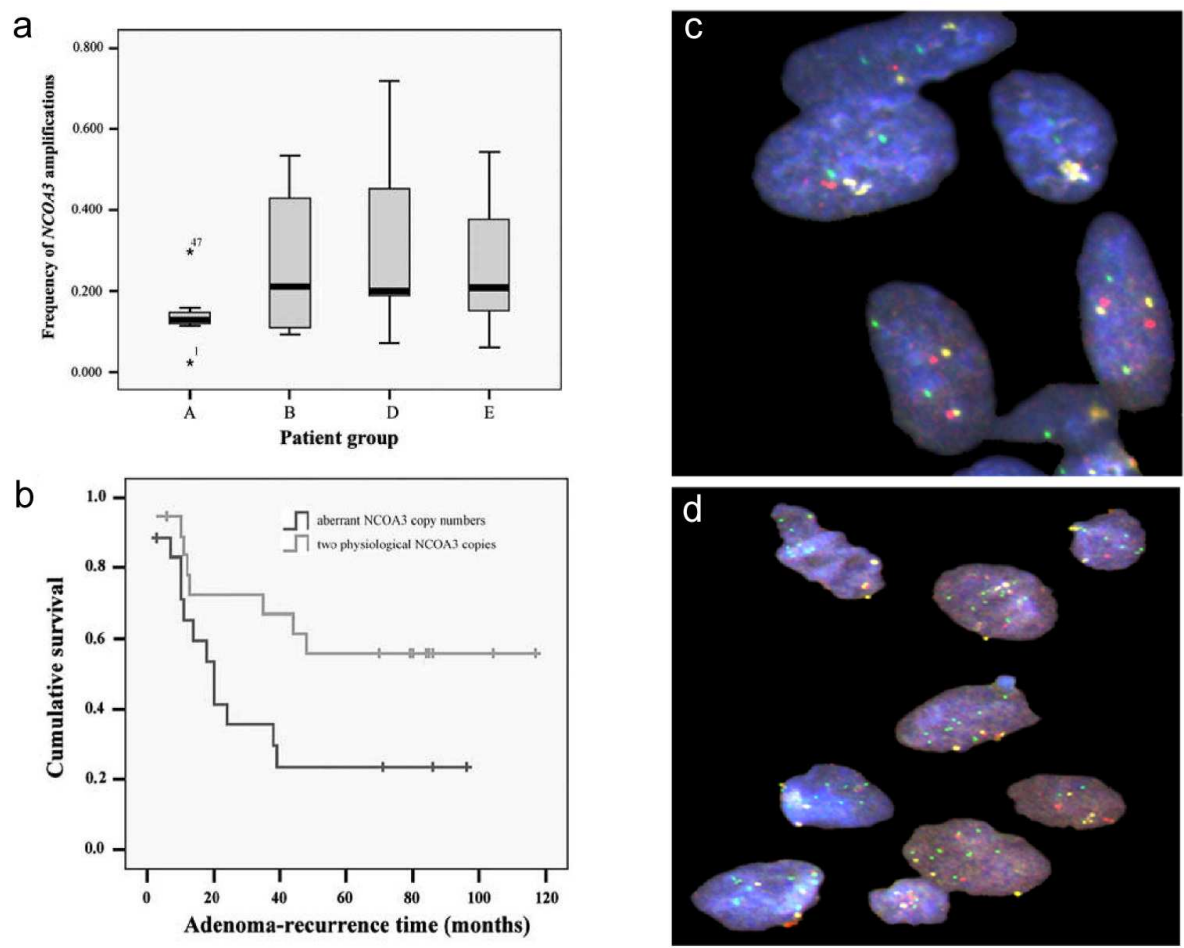

Fig. 4. (a) Frequency of NCOA3 amplifications according to patient groups (A, patients without adenoma recurrence and without carcinoma; (B) patients with adenoma recurrence but without carcinoma; (D) patients without adenoma recurrence but with carcinoma; (E) patients with adenoma recurrence and with carcinoma). (b) Adenoma recurrence-free survival time depending on NCOA3 copy numbers. (c) Physiological copy numbers in diploid and (d) aberrant copy numbers in aneuploid adenomas for CEP17 (yellow), NCOA3 (green) and TP53 (red). Modified from (Habermann et al. 2011).

Fourth, the most frequently observed alterations overall were a gain of EGFR (36.2\%) and $R A B 20(34.2 \%)$. Although the frequency of these two aberrations was increased in the carcinoma samples (EGFR, 44\%/RAB20,41.4\%), there was no difference between patients 
with and without malignancy. Based on the presented above results one could conclude that genomic instability in colorectal adenomas is reflected by genomic amplification of the oncogenes EGFR, MYC, NCOA3, and RAB20. These amplifications could be indicative for adenoma recurrence and for the presence of synchronous carcinomas. Detection of such amplifications using FISH could therefore contribute to the assessment of individual progression to malignancy.

\section{Aneuploidy-associated gene expression}

\subsection{Aneuploidy-associated gene expression in colorectal cell lines}

The correlation of nuclear aneuploidy with conserved patterns of chromosomal aberrations and gene specific signal enumerations with prognosis prompted us to analyze the immediate consequences of chromosomal copy number changes at the gene expression level. For this purpose, microcell-mediated chromosome transfer was used to introduce extra copies of chromosomes 3, 7, and 13 into the diploid colorectal cancer cell line DLD1 (Upender et al. 2004). The introduction of all three chromosomes individually resulted in a significant increase in average gene expression on the trisomic chromosome (all $\mathrm{P}<0.0001$ ). In order to assess whether this effect was specific for DLD1 per se or specific for the tissue of origin (colon), we also determined the effect of an additional copy of chromosome 3 in a mammary epithelial cell line (hTERT-HME). The introduction of an extra copy of chromosome 3 into the telomerase immortalized, karyotypically normal mammary epithelial cells resulted as well in an increase in the average gene expression of chromosome 3 genes $(\mathrm{P}<0.0001$, Figure 5). An additional analysis at the level of chromosome arms did not reveal additional changes in any of the derivative cell lines.

In addition to analysis of average, chromosome-specific gene expression levels for the introduced chromosomes, we also identified additional deregulated genes throughout the genome. The influence of the three trisomies at the individual gene expression level was examined by considering only genes with expression ratios $>2.0$ (up-regulated) or $<0.5$ (down-regulated) when compared with the parental cell line. For clone DLD1 +7 , only $18 \%$ (35 of 194) of the differentially expressed genes (DEGs) with known locus information mapped to chromosome 7 and 32 of these were up-regulated (Table 1). Regarding chromosome 13, only 6\% (10 of 162) mapped to chromosome 13, of which all were upregulated (Table 1). The trisomy of chromosome 3 in DLD1 revealed 12\% (17 of 144) to map to this chromosome and all were up-regulated (Table 1). The introduction of the same trisomy 3 into the hTERT-HME cells yielded 17\% (23 of 135) of the differentially expressed genes mapping to chromosome 3 , of which 21were up-regulated (Table 1).

Strikingly, no genes were affected in common among any of the four derivative cell clones. Five percent of all genes on the array mapped to each of chromosomes 7 and 3. For chromosome 13, the percentage was $1.7 \%$. The observed percentages of up-regulated genes located on chromosomes 7 and 3 were each $>20 \%$, and the observed percentage of upregulated genes residing on chromosome 13 was $>10 \%$. Thus, the percentages of upregulated genes residing on the introduced chromosomes were substantially greater than would have been expected by chance if up-regulation occurred at random. In contrast, the percentages of down-regulated genes residing on the introduced chromosomes were no more than expected by chance. Thus, the effect of a very specific increase in average 

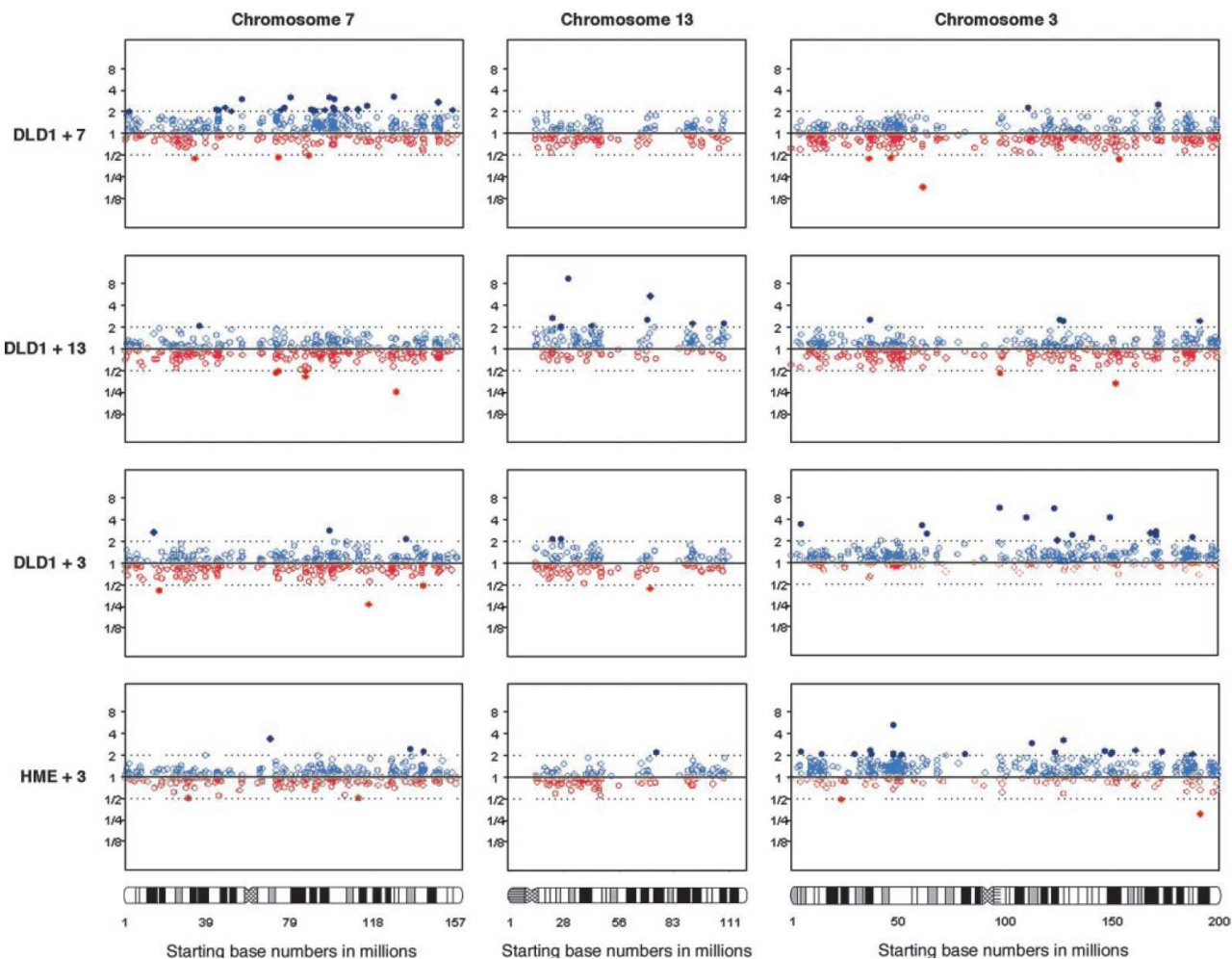

Fig. 5. Global gene expression profiles. Each scatter-plot displays all genes and their corresponding normalized expression ratio values along the length of each chromosome. Values in open light blue circles and open light orange circles represent ratio values between 0.5 and 2.0. Dark blue dots represent expression ratios $>2.0$ and dark orange dots are ratios $<0.5$. The $X$ axis shows the starting base pair location of each gene (Upender et al. 2004).

\begin{tabular}{|c|c|c|c|c|}
\hline & DLD1 + 7 & DLD1 + 13 & DLD1 + 3 & $\mathrm{HME}+3$ \\
\hline $\begin{array}{l}\text { No. of genes two-fold } \\
\text { altered }\end{array}$ & 202 & 164 & 148 & 140 \\
\hline No. of up-regulated genes & 155 & 92 & 81 & 91 \\
\hline Map on chromosome & 32 & 10 & 17 & 21 \\
\hline Map off chromosome & 117 & 82 & 64 & 66 \\
\hline Map unknown & 6 & 0 & 0 & 4 \\
\hline $\begin{array}{l}\text { No. of down-regulated } \\
\text { genes }\end{array}$ & 47 & 72 & 67 & 49 \\
\hline Map on chromosome & 3 & 0 & 0 & 2 \\
\hline Map off chromosome & 42 & 70 & 63 & 46 \\
\hline Map unknown & 2 & 2 & 4 & 1 \\
\hline
\end{tabular}

NOTE. Genes up or down regulated (normalized ratio $>2.0$ and < 0.5, respectively; (Upender et al. 2004).

Table 1 . Summary of 2-fold altered gene lists 
expression of genes on the trisomic chromosomes is further supported by an expression increase of a significant number of individual genes located on those chromosomes. Furthermore, a large number of genes located on diploid chromosomes in these derivative cell clones was also significantly increased in expression, hereby revealing a more complex global transcriptional deregulation.

The phenomenon of trisomy-associated expression alterations in the cell line model described above was further confirmed by a correlation analysis of chromosomal aberrations and gene expression changes in 16 normal mucosa specimens, 17 adenomas, 20 primary colorectal carcinomas, and 13 liver metastases (Habermann et al. 2007). In particular, we found average gene expression changes for those chromosome arms that showed copy number changes including $7 p, 7 q, 8 p, 8 q, 13 q, 18 p, 18 q, 20 p$ and $20 q$ in colorectal carcinomas.

\subsection{Aneuploidy-associated gene expression in breast carcinoma}

Comparable to colorectal cancer, aneuploidy also has a direct impact on the prognosis of patients suffering from breast cancer. In this disease, aneuploidy serves as an indicator of poor prognosis independent from established parameters such as lymph node status and other clinical and histomorphological variables (Auer, Caspersson, and Wallgren 1980; Auer et al. 1984; Heselmeyer-Haddad et al. 2002; Ried et al. 1995). Consistent with these results, the differentiation of aneuploidy and near diploidy in genomically stable and unstable cell populations using the Stemline Scatter Index (SSI) has shown that patients with genomically stable tumors have a significantly better prognosis than those with unstable ones (Kronenwett et al. 2004; Kronenwett et al. 2006). To evaluate potential differences in gene expression patterns between genomically stable and unstable breast carcinomas, 48 breast carcinomas were assessed by gene expression profiling on microarrays (Habermann et al. 2009): 17 diploid tumors were genomically stable (dGS), 15 tumors assessed as aneuploid, yet genomically stable (aGS), and 16 carcinomas were classified as aneuploid and genomically unstable (aGU). No differences were observed among the three groups regarding patients' age, tumor size and number of lymph node metastases. The higher degree of genomic instability in the aGU group was also reflected in an increase in chromosomal copy number changes as measured by CGH. A detailed summary and comparison of chromosomal aberrations between the three groups is presented in Figure 6 .

Chromosomal aberrations in the genomically stable tumors (dGS and aGS) were mainly restricted to gains of chromosome $1 \mathrm{q}$ and 16p and accompanied by losses on chromosome 16q. In contrast, aGU tumors showed more diverse changes including a frequent gain of the long arm of chromosome 17, the mapping position of the ERBB2 oncogene. The similarity of the genomically stable (dGS and aGS) compared to the genomically unstable (aGU) tumors was further supported by gene expression profiles: pair-wise comparisons of the three groups showed that 38 genes were commonly differentially expressed for the comparisons $a G U$ versus $d G S$ and $a G U$ versus aGS, whereas only two genes were commonly observed in the comparisons $a G U$ versus $a G S$ and $a G S$ versus $d G S$, and three genes among aGS versus $d G S$ and $a G U$ versus $d G S$. The gene lists describing exclusive differences between all groups can be obtained from Habermann et al. (Habermann et al. 2009). In summary, both, 

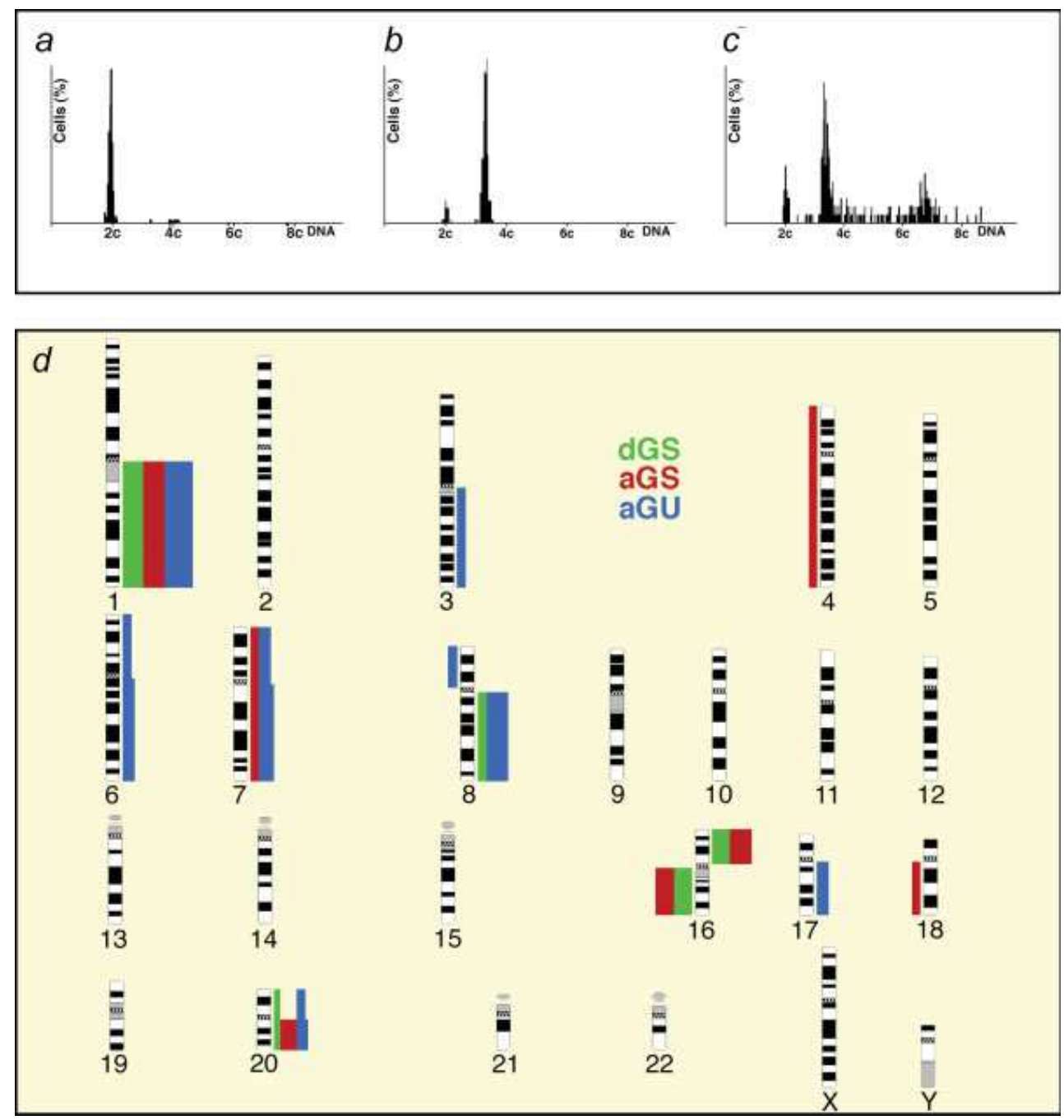

Fig. 6. Genomic instability in breast cancer: Examples of DNA histograms of (a) diploid, genomically stable tumors (dGS), (b) aneuploid, yet genomically stable tumors (aGS), and (c) aneuploid and genomically unstable (aGU) tumors. Note the profound scattering of the ploidy stemline in (c) (for details of the ploidy classification see (Kronenwett et al. 2004). (d) Summary of genomic imbalances in 15 dGS (green), 12 aGS (red), and 11 aGU (blue) breast carcinomas analyzed by comparative genomic hybridization. Bars on the left side of the chromosome ideogram denote a loss of sequence in the tumor genome, while bars on the right side designate a gain. The width of the bars indicates the relative frequency of gains and losses observed (Habermann et al. 2009). 
chromosomal alterations and patterns of differentially expressed genes suggest that tumors classified as genetically unstable differed substantially from the genetically stable ones, regardless of the actual ploidy status (i.e., the position of the stemline which is at $2 \mathrm{c}$ in the dGS and different from $2 \mathrm{c}$ in the aGS).

In order to further explore the biological relevance of our gene expression differences in the genomically stable versus unstable groups, we evaluated the usefulness of our expression profiles for predicting disease outcome in previously published independent datasets. For this purpose, the classification of our samples into genomically stable and unstable carcinomas was based on a 12-gene-genome instability signature (Habermann et al. 2009). This gene set, which discerned the stable from unstable tumors, was then applied for predicting cancer outcomes in independent datasets reported by Sorlie et al. (Sorlie et al. 2003), van de Vijver et al. (van de Vijver et al. 2002), and Sotiriou et al. (Sotiriou et al. 2003). Each patient in the three validation cohorts was classified as being more similar to either the genomically stable or unstable signature, based on the correlation of this patient's gene expression pattern with the average expression profiles of the genomically stable and unstable samples in our dataset. Kaplan-Meier analyses showed that patients defined to have genomic unstable carcinomas were associated with a distinct shorter relapse-free survival and metastasis-free survival $(\mathrm{p}<0.04)$ in the patient cohorts from Sorlie et al. (Sorlie et al. 2003), van de Vijver et al. (van de Vijver et al. 2002), and Sotiriou et al. (Sotiriou et al. 2003). Furthermore, patients presenting tumors with genomic instability had a remarkably different, shorter overall survival in Kaplan-Meier analyses $(p<0.025)$ as shown in Figure 7.

It was further shown, that the 12-gene signature is independent of clinicopathologic factors such as lymph node status, the NIH criteria, the St. Gallen criteria, and grading used for breast cancer prognostication (Habermann et al. 2009). Furthermore, the 12-gene genome instability signature revealed a remarkable concordance with independent classification systems for specific prognostic subtypes, i.e., luminal A and B, basal, ERBB2+, and normallike (Sorlie et al. 2001; Sorlie et al. 2003; Perou et al. 2000; Bergamaschi et al. 2006): of the 28 genomically stable tumors in our collection, 24 were assigned to subtypes luminal A $(n=18)$ or normal-like $(n=6)$. Only four tumors were assigned to the ERBB2+ group. In contrast, all but one genomically unstable tumor $(n=16)$ was assigned to either the ERBB2+ group $(n=$ 10 ) or the basal group $(n=5)$, indicating pour prognosis. Of note, most of our genomically unstable tumors showed genomic amplification of chromosome arm 17q, the mapping position of the ERBB2 oncogene (Figure 6).

In addition, it was explored whether other gene expression signatures for breast cancer prognosis would allow classification of the degree of genomic instability in our samples. Specifically, the 21-gene signature of the so-called Oncotype DX assay (consisting of 16 cancer-associated genes and 5 genes included for normalization purposes) (Paik et al. 2004), and the 70-gene signature of the MammaPrint ${ }^{\circledR}$ (van de Vijver et al. 2002; van 't Veer et al. 2002) were used to predict genomic instability in our tumor collection. Twelve of the 21 genes used in the Oncotype DX test were present on our platform, whereas 21 of the 70 genes employed by MammaPrint ${ }^{\circledR}$ could be utilized in our set. Using the Oncotype DX gene set, overall prediction accuracy (measured as correct classification of unstable tumors as unstable, and stable tumors as stable) was $91 \%$, whereas the MammaPrint ${ }^{\circledR}$ set correctly classified $84 \%$ of all cases. Therefore, these results further support a close linkage between genomic instability and poor prognosis in breast cancer. 
In summary, the above data show that, firstly, differences in the degree of genomic instability were reflected in the 12-gene signature that separated our samples. Secondly, this aneuploidy-specific gene expression signature can reliably predict outcome in published datasets, and, thirdly, in turn, the gene expression signature of poor prognosis, independent of the specific platform, predicts the degree of genomic instability with convincing accuracy $(\mathrm{p}<0.001)$.

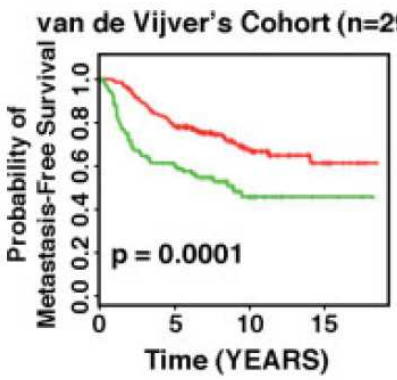

van de Vijver's Cohort $(\mathrm{n}=295)$

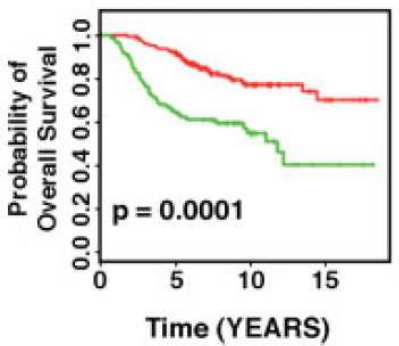

Sotiriou's Cohort ( $n=99)$

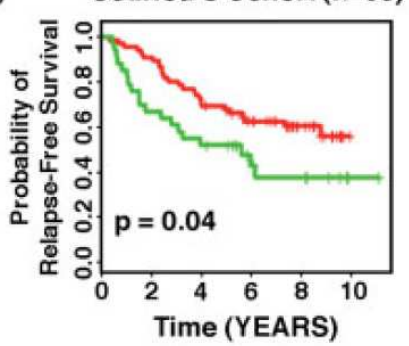

Sotiriou's Cohort $(n=99)$

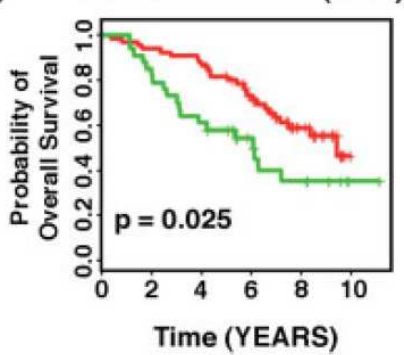

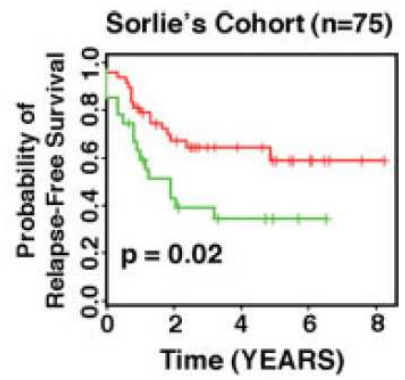

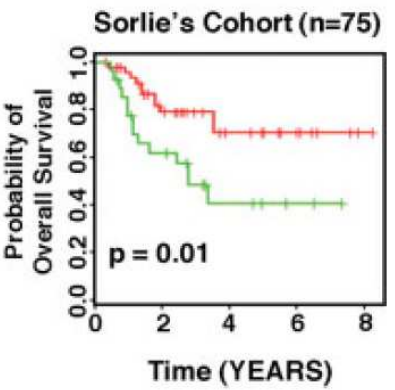

Fig. 7. Applying the 12-gene genomic instability signature for prediction of disease-free and overall survival in independent datasets using Kaplan-Meier analyses. The curves in red reflect carcinoma patients harboring the genomically stable signature, the curves in green the one representing genomic instability. For all examples, statistically significant association of genomic instability with shorter disease-free and overall survival was observed (Habermann et al. 2009).

\section{Aneuploidy-associated protein expression}

Against the background that nuclear aneuploidy correlates with cancer or cancer subtypespecific chromosomal alterations that impact on gene expression levels, we considered it highly important to elucidate if aneuploidy-associated protein expression patterns can be identified as well. Such protein expression patterns could likely unravel novel targets for improved diagnostics and potentially therapeutic interventions. Two-dimensional gel electrophoresis (2-DE) and mass-spectrometry were applied to assess protein expression profiles of colorectal cancer cell lines of defined ploidy types. Ploidy assessment determined the colorectal cancer cell lines DLD-1, HCT116, and LoVo to be diploid. In contrast, Caco-2, 
HT-29, T84, and Colo 201 were classified as aneuploid. Ploidy-type classification of cell lines was further supported by comparative genomic hybridization (CGH) and spectral karyotyping (SKY) analyses (http://www.ncbi.nlm.nih.gov/sky/).

Two independent statistical analyses revealed 38 (ANOVA analysis) and 31 (random forest) protein spots being differentially expressed between the diploid and aneuploid cell lines (Gemoll et al. 2011). Twenty-six spots were identified by peptide mass fingerprinting: eight proteins were higher and 18 lower expressed in the aneuploid than in the diploid cell lines. Based on Ingenuity Pathways Analysis, fold changes, molecular functions, and availability of antibodies, YWHAQ, CAPZA1, GNAS, PRDX2, HDAC2, and TXNL1 were selected for downstream analysis. While Western-blot fold changes of all six proteins were in accordance with 2-DE data, only three of the six proteins reached significance $(p<0.05)$ having either lower (TXNL1, CAPZA1) or higher expression (HDAC2) in the aneuploid group.

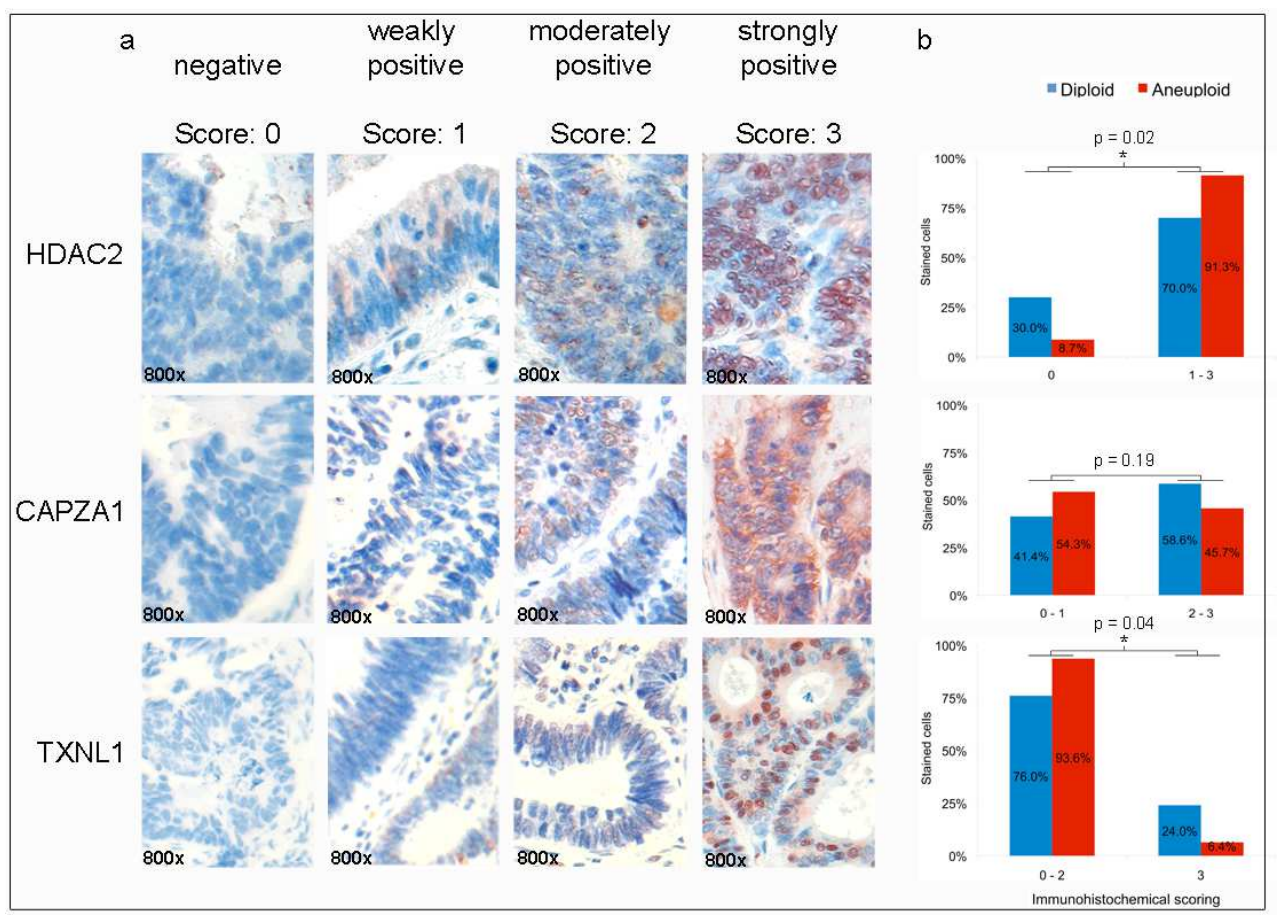

Fig. 8. (a) HDAC2, CAPZA1, and TXNL1 immunohistochemical detection in colorectal cancer specimens based on a tissue microarray. Image examples are given at 800 -fold magnification. (b) Tissue-microarray-based immunohistochemical evaluation of HDAC2, CAPZA1, and TXNL1 comparing diploid versus aneuploid colorectal carcinoma specimens. Immunoreactivity was scored with " 0 " showing no positivity, " 1 " presenting up to $20 \%$ immunopositive cells, " 2 " up to $50 \%$, and " 3 " above $50 \%$ stained cells. Barplots of the TMA analysis confirmed HDAC2 and TXNL1 as significantly (asterisk) differentially expressed proteins between diploid and aneuploid tumors (Gemoll et al. 2011). 
For proof of clinical relevance we chose those three proteins for tissue microarray (TMA)based immunohistochemistry assessment. As shown in Figure 8, HDAC2 nuclear immunopositivity (score 1, 2, and 3) was more frequently present in aneuploid $(91.3 \%)$ than in diploid $(70 \%)$ carcinomas $(\mathrm{P}=0.02)$. For $\mathrm{TXNL1}$, strong nuclear immunoreactivity (score $3)$ was more frequently observed in diploid $(24 \%)$ than in aneuploid carcinomas $(6.4 \%, \mathrm{P}=$ 0.04). CAPZA1 immunohistochemistry showed a similar trend as in Western-blot and 2-DE analysis, however, did not reach significance. By comparing immunopositivity between normal adjacent mucosa and all carcinoma specimens irrespective of their ploidy status, we detected significantly stronger immunopositivity in the carcinomas for HDAC2 $(\mathrm{P}<0.001)$ and TXNL1 $(\mathrm{P}=0.026)$.

The TXNL1 gene encodes a protein that belongs to the thioredoxin family of small redox active proteins. TXNL1 overexpression can increase the transcriptional repressor function through its binding to the transcription factor B-Myb (Kim et al. 2006). Thus, TXNL1 overexpression specifically predisposes to arrest in the G0/G1 phase of the cell cycle. Overexpression in diploid malignancies could therefore help to maintain genomic stability. HDAC2 plays an important role in transcriptional regulation and cell cycle progression (Harms and Chen 2007). HDAC2 is overexpressed in several tumor entities, including colon cancer (Song et al. 2005; Ashktorab et al. 2009). Interestingly, HDAC2 overexpression seems to be induced by APC loss and appears to be sufficient on its own to prevent apoptosis, thus favoring the development of genomic instability and tumor growth (Zhu et al. 2004). The inhibition of HDAC in combination with chemotherapy (doxorubicin) is currently assessed in phase I clinical trials. HDAC2 overexpression in the primary tumor serves as a predictive marker for efficient HDAC inhibition (Munster et al. 2009). Our data show a close correlation of HDAC2 overexpression, aneuploidy, and poor prognosis. It seems therefore reasonable that HDAC2 overexpression is a mere reflection of aneuploidy and that patients, in particular those with aneuploid tumors could benefit from treatment with HDACinhibitors. The fact that more than $70 \%$ of colorectal cancers are aneuploid makes this even more compelling.

\section{Conclusions}

DNA aneuploidy is a defining feature of human cancers of epithelial origin, i.e., the carcinomas. Disease-specific chromosomal aneuploidies develop before the transition to invasive disease, e.g., in ulcerative colitis and colorectal adenomas. These early chromosomal alterations are maintained in primary carcinomas and are complemented by additional, recurrent chromosomal aberrations that persist in local and distant metastases. Chromosomal aneuploidy not only has an impact on the expression levels of resident genes but also correlates with protein expression. Such aneuploidy-associated protein expression patterns could reveal novel diagnostic and therapeutic targets. Our general conclusions were supported by the findings of Sinicrope et al., Bosari et al., and Yildirim-Assaf et al. showing that patients with aneuploid tumors had a worse outcome compared to patients with euploid tumors (Sinicrope, Rego, Halling, et al. 2006; Bosari et al. 1992; Yildirim-Assaf et al. 2007). Despite this clear demonstration of an association of aneuploidy and outcome the American Society of Clinical Oncology (ASCO) does not recommend ploidy assessment in clinical routine. In our opinion, this should be reconsidered, also because meta-analysis revealed results clearly indicating the prognostic impact of aneuploidy on colorectal and 
other cancers (Araujo et al. 2007; Walther, Houlston, and Tomlinson 2008; Schulze and Petersen 2011). Overall, the assessment of nuclear aneuploidy by image cytometry could become routine practice to assist in predicting individual cancer risk and in disease prognostication in solid tumors.

\section{Future perspectives}

DNA ploidy measurements in premalignant lesions could profoundly improve individual risk assessment for imminent colorectal cancer development. Furthermore, individual risk stratification and survival prognosis in solid malignancies, including colorectal and breast cancer, could benefit from the assessment of nuclear DNA content and the visualization of disease-specific chromosomal aneuploidies. However, large multicenter prospective studies are warranted to further corroborate the value of measurement of aneuploidy for an improved screening and better prognostication in solid malignancies. For this purpose we have initiated the North German Tumorbank of Colorectal Cancer (Acronym: ColoNet) that currently comprises patients of the universities and clinics of Hamburg, Lübeck, Rostock, Greifswald, Bad Oldesloe, Berlin-Buch and associated private practices in Northern Germany. Within this network and in collaboration with the Surgical Center for Translational Oncology-Lübeck (SCTO-L) as well as the clinical partners at the greater Stockholm area we will investigate the benefit of ploidy measurements for individual risk and prognosis assessment in epithelial malignancies.

\section{Acknowledgements}

We thank all members of the laboratories of Gert Auer, Jens Habermann, Hans Jörnvall, and Thomas Ried, and all colleagues at the Department of Surgery, Department of Pathology and Unit of Gastroenterology at the University of Lübeck who made these studies possible. In particular, we are indebted to Constanze A. Brucker, Michael J. Difilippantonio, Marco Gerling and Kerstin Heselmeyer-Haddad for their valuable input. Furthermore we gratefully acknowledge the intramural funding of the National Institutes of Health, the Karolinska Institutet, the University of Lübeck and the Werner and Clara Kreitz Foundation, the Ad Infinitum Foundation, the Swedish Cancer Society, the Cancer Society Stockholm, the Swedish Research Council, the King Gustav V Jubilee Fund, the Wallenberg Consortium North, and the Knut and Alice Wallenberg Foundation. These studies were performed in connection with the Surgical Center for Translational Oncology - Lübeck (SCTO-L) and were based on sample collections of the North German Tumorbank of Colorectal Cancer (DKH \#108446) and the Karolinska Hospital.

\section{Abbreviations}

$\begin{array}{ll}\text { 2-DE } & \text { Two-dimensional gel electrophoresis } \\ \text { aGS } & \text { Aneuploid genomically stable } \\ \text { aGU } & \text { Aneuploid genomically unstable } \\ \text { ANOVA } & \text { Analysis of variance } \\ \text { ASCO } & \text { American Society of Clinical Oncology } \\ \text { CDK } & \text { Cyclin-dependent kinase } \\ \text { CGH } & \text { Comparative genomic hybridization }\end{array}$




$\begin{array}{ll}\text { CI } & \text { Confidence intervall } \\ \text { DEG } & \text { Differentially expressed gene } \\ \text { dGS } & \text { Diploid genomically stable } \\ \text { FISH } & \text { Fluorescence in situ hybridization } \\ \text { OR } & \text { Odds ratio } \\ \text { SCC } & \text { Sporadic colorectal cancer } \\ \text { SKY } & \text { Spectral karyotyping } \\ \text { SSI } & \text { Stemline Scatter Index } \\ \text { TMA } & \text { Tissue microarray } \\ \text { UC } & \text { Ulcerative colitis } \\ \text { UCC } & \text { Ulcerative colitis-associated colorectal cancer } \\ \text { UICC } & \text { Union internationale contre le cancer }\end{array}$

\section{References}

Allshire, R. C. 1997. Centromeres, checkpoints and chromatid cohesion. Curr Opin Genet Dev 7 (2):264-73.

Araujo, S. E., W. M. Bernardo, A. Habr-Gama, D. R. Kiss, and I. Cecconello. 2007. DNA ploidy status and prognosis in colorectal cancer: a meta-analysis of published data. Diseases of the colon and rectum 50 (11):1800-10.

Ashktorab, H., K. Belgrave, F. Hosseinkhah, H. Brim, M. Nouraie, M. Takkikto, S. Hewitt, E. L. Lee, R. H. Dashwood, and D. Smoot. 2009. Global histone H4 acetylation and HDAC2 expression in colon adenoma and carcinoma. Dig Dis Sci 54 (10):2109-17.

Auer, G., E. Eriksson, E. Azavedo, T. Caspersson, and A. Wallgren. 1984. Prognostic significance of nuclear DNA content in mammary adenocarcinomas in humans. Cancer Res 44 (1):394-6.

Auer, G., J. Ono, M. Nasiell, T. Caspersson, H. Kato, C. Konaka, and Y. Hayata. 1982. Reversibility of bronchial cell atypia. Cancer Res 42 (10):4241-7.

Auer, G. U., T. O. Caspersson, and A. S. Wallgren. 1980. DNA content and survival in mammary carcinoma. Anal Quant Cytol 2 (3):161-5.

Aust, D. E., R. F. Willenbucher, J. P. Terdiman, L. D. Ferrell, C. G. Chang, D. H. Moore, 2nd, A. Molinaro-Clark, G. B. Baretton, U. Loehrs, and F. M. Waldman. 2000. Chromosomal alterations in ulcerative colitis-related and sporadic colorectal cancers by comparative genomic hybridization. Hum Pathol 31 (1):109-14.

Barrett, J. C., M. Oshimura, N. Tanaka, and T. Tsutsui. 1985. Role of aneuploidy in early and late stages of neoplastic progression of Syrian hamster embryo cells in culture. Basic Life Sci 36:523-38.

Bergamaschi, A., Y. H. Kim, P. Wang, T. Sorlie, T. Hernandez-Boussard, P. E. Lonning, R. Tibshirani, A. L. Borresen-Dale, and J. R. Pollack. 2006. Distinct patterns of DNA copy number alteration are associated with different clinicopathological features and gene-expression subtypes of breast cancer. Genes, chromosomes $\mathcal{E}$ cancer 45 (11):1033-40.

Bomme, L., G. Bardi, N. Pandis, C. Fenger, O. Kronborg, and S. Heim. 1994. Clonal karyotypic abnormalities in colorectal adenomas: clues to the early genetic events in the adenoma-carcinoma sequence. Genes, Chromosomes \& Cancer 10 (3):190-6. 
Bosari, S., A. K. Lee, B. D. Wiley, G. J. Heatley, W. M. Hamilton, and M. L. Silverman. 1992. DNA quantitation by image analysis of paraffin-embedded colorectal adenocarcinomas and its prognostic value. Modern pathology : an official journal of the United States and Canadian Academy of Pathology, Inc 5 (3):324-8.

Boveri, T. 1914. Zur Frage der Entstehung maligner Tumoren. Jena: Gustav Fischer.

Burmer, G. C., P. S. Rabinovitch, and L. A. Loeb. 1991. Frequency and spectrum of c-Ki-ras mutations in human sporadic colon carcinoma, carcinomas arising in ulcerative colitis, and pancreatic adenocarcinoma. Environ Health Perspect 93:27-31.

Cahill, D. P., C. Lengauer, J. Yu, G. J. Riggins, J. K. Willson, S. D. Markowitz, K. W. Kinzler, and B. Vogelstein. 1998. Mutations of mitotic checkpoint genes in human cancers. Nature 392 (6673):300-3.

Caspersson, T. O. 1979. Quantitative tumor cytochemistry--G.H.A. Clowes Memorial Lecture. Cancer Res 39 (7 Pt 1):2341-5.

Caspersson, T., L. Zech, C. Johansson, and E. J. Modest. 1970. Identification of human chromosomes by DNA-binding fluorescent agents. Chromosoma 30 (2):215-27.

Clausen, O. P., S. N. Andersen, H. Stroomkjaer, V. Nielsen, T. O. Rognum, L. Bolund, and S. Koolvraa. 2001. A strategy combining flow sorting and comparative genomic hybridization for studying genetic aberrations at different stages of colorectal tumorigenesis in ulcerative colitis. Cytometry 43 (1):46-54.

D'Amours, D., and S. P. Jackson. 2002. The Mre11 complex: at the crossroads of dna repair and checkpoint signalling. Nat Rev Mol Cell Biol 3 (5):317-27.

Desper, R., F. Jiang, O. P. Kallioniemi, H. Moch, C. H. Papadimitriou, and A. A. Schaffer. 2000. Distance-based reconstruction of tree models for oncogenesis. J Comput Biol 7 (6):789-803.

Donnellan, R., and R. Chetty. 1999. Cyclin E in human cancers. Faseb J 13 (8):773-80.

Duesberg, P., C. Rausch, D. Rasnick, and R. Hehlmann. 1998. Genetic instability of cancer cells is proportional to their degree of aneuploidy. Proc Natl Acad Sci U S A 95 (23):13692-7.

Fearon, E. R., and B. Vogelstein. 1990. A genetic model for colorectal tumorigenesis. Cell 61 (5):759-67.

Forozan, F., R. Karhu, J. Kononen, A. Kallioniemi, and O. P. Kallioniemi. 1997. Genome screening by comparative genomic hybridization. Trends Genet 13 (10):405-9.

Fozard, J. B., P. Quirke, M. F. Dixon, G. R. Giles, and C. C. Bird. 1986. DNA aneuploidy in ulcerative colitis. Gut 27 (12):1414-8.

Gemoll, T., U. J. Roblick, S. Szymczak, T. Braunschweig, S. Becker, B. W. Igl, H. P. Bruch, A. Ziegler, U. Hellman, M. J. Difilippantonio, T. Ried, H. Jornvall, G. Auer, and J. K. Habermann. 2011. HDAC2 and TXNL1 distinguish aneuploid from diploid colorectal cancers. Cellular and molecular life sciences : CMLS 68 (19):3261-74.

Gerling, M., K. F. Meyer, K. Fuchs, B. W. Igl, B. Fritzsche, A. Ziegler, F. Bader, P. Kujath, H. Schimmelpenning, H. P. Bruch, U. J. Roblick, and J. K. Habermann. 2010. High Frequency of Aneuploidy Defines Ulcerative Colitis-Associated Carcinomas: A Comparative Prognostic Study to Sporadic Colorectal Carcinomas. Annals of surgery [Epub ahead of print].

Ghadimi, B. M., D. L. Sackett, M. J. Difilippantonio, E. Schrock, T. Neumann, A. Jauho, G. Auer, and T. Ried. 2000. Centrosome amplification and instability occurs 
exclusively in aneuploid, but not in diploid colorectal cancer cell lines, and correlates with numerical chromosomal aberrations. Genes, Chromosomes $\mathcal{E}$ Cancer 27 (2):183-90.

Giaretti, W., T. Venesio, C. Prevosto, F. Lombardo, J. Ceccarelli, S. Molinu, and M. Risio. 2004. Chromosomal instability and APC gene mutations in human sporadic colorectal adenomas. J Pathol 204 (2):193-9.

Habermann, J. K., C. A. Brucker, S. Freitag-Wolf, K. Heselmeyer-Haddad, S. Kruger, L. Barenboim, T. Downing, H. P. Bruch, G. Auer, U. J. Roblick, and T. Ried. 2011. Genomic instability and oncogene amplifications in colorectal adenomas predict recurrence and synchronous carcinoma. Mod Pathol 24 (4):542-55.

Habermann, J. K., J. Doering, S. Hautaniemi, U. J. Roblick, N. K. Bundgen, D. Nicorici, U. Kronenwett, S. Rathnagiriswaran, R. K. Mettu, Y. Ma, S. Kruger, H. P. Bruch, G. Auer, N. L. Guo, and T. Ried. 2009. The gene expression signature of genomic instability in breast cancer is an independent predictor of clinical outcome. International journal of cancer. Journal international du cancer 124 (7):1552-64.

Habermann, J. K., U. Paulsen, U. J. Roblick, M. B. Upender, L. M. McShane, E. L. Korn, D. Wangsa, S. Kruger, M. Duchrow, H. P. Bruch, G. Auer, and T. Ried. 2007. Stagespecific alterations of the genome, transcriptome, and proteome during colorectal carcinogenesis. Genes, Chromosomes \& Cancer 46 (1):10-26.

Habermann, J. K., M. B. Upender, U. J. Roblick, S. Kruger, S. Freitag, H. Blegen, H. P. Bruch, H. Schimmelpenning, G. Auer, and T. Ried. 2003. Pronounced chromosomal instability and multiple gene amplifications characterize ulcerative colitisassociated colorectal carcinomas. Cancer Genet Cytogenet 147 (1):9-17.

Habermann, J., C. Lenander, U. J. Roblick, S. Kruger, D. Ludwig, A. Alaiya, S. Freitag, L. Dumbgen, H. P. Bruch, E. Stange, S. Salo, K. Tryggvason, G. Auer, and H. Schimmelpenning. 2001. Ulcerative colitis and colorectal carcinoma: DNA-profile, laminin-5 gamma2 chain and cyclin A expression as early markers for risk assessment. Scand J Gastroenterol 36 (7):751-8.

Handa, K., M. Yamakawa, H. Takeda, S. Kimura, and T. Takahashi. 1999. Expression of cell cycle markers in colorectal carcinoma: superiority of cyclin A as an indicator of poor prognosis. Int J Cancer 84 (3):225-33.

Harms, K. L., and X. Chen. 2007. Histone deacetylase 2 modulates p53 transcriptional activities through regulation of p53-DNA binding activity. Cancer Res 67 (7):314552.

Heselmeyer-Haddad, K., N. Chaudhri, P. Stoltzfus, J. C. Cheng, K. Wilber, L. Morrison, G. Auer, and T. Ried. 2002. Detection of chromosomal aneuploidies and gene copy number changes in fine needle aspirates is a specific, sensitive, and objective genetic test for the diagnosis of breast cancer. Cancer Res 62 (8):2365-9.

Heselmeyer, K., E. Schrock, S. du Manoir, H. Blegen, K. Shah, R. Steinbeck, G. Auer, and T. Ried. 1996. Gain of chromosome 3q defines the transition from severe dysplasia to invasive carcinoma of the uterine cervix. Proc Natl Acad Sci U S A 93 (1):479-84.

Hittelman, W. N. 2001. Genetic instability in epithelial tissues at risk for cancer. Ann N Y Acad Sci 952:1-12.

Holzmann, K., B. Klump, F. Borchard, C. J. Hsieh, A. Kuhn, V. Gaco, M. Gregor, and R. Porschen. 1998. Comparative analysis of histology, DNA content, p53 and Ki-ras 
mutations in colectomy specimens with long-standing ulcerative colitis. Int J Cancer 76 (1):1-6.

Holzmann, K., M. Weis-Klemm, B. Klump, C. J. Hsieh, F. Borchard, M. Gregor, and R. Porschen. 2001. Comparison of flow cytometry and histology with mutational screening for p53 and Ki-ras mutations in surveillance of patients with longstanding ulcerative colitis. Scand J Gastroenterol 36 (12):1320-6.

Hopman, A. H., F. C. Ramaekers, A. K. Raap, J. L. Beck, P. Devilee, M. van der Ploeg, and G. P. Vooijs. 1988. In situ hybridization as a tool to study numerical chromosome aberrations in solid bladder tumors. Histochemistry 89 (4):307-16.

Howard, A., and S. R. Pelc. 1951. Nuclear incorporation of p32 as demonstrated by autoradiographs. Exp Cell Res 2:178.

Jallepalli, P. V., and C. Lengauer. 2001. Chromosome segregation and cancer: cutting through the mystery. Nat Rev Cancer 1 (2):109-17.

Kallioniemi, A., O. P. Kallioniemi, D. Sudar, D. Rutovitz, J. W. Gray, F. Waldman, and D. Pinkel. 1992. Comparative genomic hybridization for molecular cytogenetic analysis of solid tumors. Science 258 (5083):818-21.

Kern, S. E., M. Redston, A. B. Seymour, C. Caldas, S. M. Powell, S. Kornacki, and K. W. Kinzler. 1994. Molecular genetic profiles of colitis-associated neoplasms. Gastroenterology 107 (2):420-8.

Kim, K. Y., J. W. Lee, M. S. Park, M. H. Jung, G. A. Jeon, and M. J. Nam. 2006. Expression of a thioredoxin-related protein-1 is induced by prostaglandin $\mathrm{E}(2)$. Int J Cancer 118 (7):1670-9.

Knudson, A. G., Jr. 1979. Hereditary cancer. Jama 241 (3):279.

Knuutila, S., A. M. Bjorkqvist, K. Autio, M. Tarkkanen, M. Wolf, O. Monni, J. Szymanska, M. L. Larramendy, J. Tapper, H. Pere, W. El-Rifai, S. Hemmer, V. M. Wasenius, V. Vidgren, and Y. Zhu. 1998. DNA copy number amplifications in human neoplasms: review of comparative genomic hybridization studies. Am J Pathol 152 (5):1107-23.

Kops, G. J., B. A. Weaver, and D. W. Cleveland. 2005. On the road to cancer: aneuploidy and the mitotic checkpoint. Nature reviews. Cancer 5 (10):773-85.

Kronenwett, U., S. Huwendiek, C. Ostring, N. Portwood, U. J. Roblick, Y. Pawitan, A. Alaiya, R. Sennerstam, A. Zetterberg, and G. Auer. 2004. Improved grading of breast adenocarcinomas based on genomic instability. Cancer Res 64 (3):904-9.

Kronenwett, U., A. Ploner, A. Zetterberg, J. Bergh, P. Hall, G. Auer, and Y. Pawitan. 2006. Genomic instability and prognosis in breast carcinomas. Cancer epidemiology, biomarkers \& prevention : a publication of the American Association for Cancer Research, cosponsored by the American Society of Preventive Oncology 15 (9):1630-5.

Lengauer, C., K. W. Kinzler, and B. Vogelstein. 1998. Genetic instabilities in human cancers. Nature 396 (6712):643-9.

Liao, C., S. Q. Li, X. Wang, S. Muhlrad, A. Bjartell, and D. J. Wolgemuth. 2004. Elevated levels and distinct patterns of expression of A-type cyclins and their associated cyclin-dependent kinases in male germ cell tumors. Int J Cancer 108 (5):654-64.

Loeb, K. R., and L. A. Loeb. 1999. Genetic instability and the mutator phenotype. Studies in ulcerative colitis. Am J Pathol 154 (6):1621-6.

Loeb, K. R., and L. A. Loeb 2000. Significance of multiple mutations in cancer. Carcinogenesis 21 (3):379-85. 
Lofberg, R., O. Brostrom, P. Karlen, A. Ost, and B. Tribukait. 1992. DNA aneuploidy in ulcerative colitis: reproducibility, topographic distribution, and relation to dysplasia. Gastroenterology 102 (4 Pt 1):1149-54.

Makiyama, K., M. Tokunaga, M. Itsuno, W. Zea-Iriarte, K. Hara, and T. Nakagoe. 1995. DNA aneuploidy in a case of rectosigmoid adenocarcinoma complicated by ulcerative colitis. J Gastroenterol 30 (2):258-63.

Munster, P. N., D. Marchion, S. Thomas, M. Egorin, S. Minton, G. Springett, J. H. Lee, G. Simon, A. Chiappori, D. Sullivan, and A. Daud. 2009. Phase I trial of vorinostat and doxorubicin in solid tumours: histone deacetylase 2 expression as a predictive marker. Br J Cancer 101 (7):1044-50.

Nigg, E. A. 1996. Cyclin-dependent kinase 7: at the cross-roads of transcription, DNA repair and cell cycle control? Current opinion in cell biology 8 (3):312-7.

Nowak, M. A., N. L. Komarova, A. Sengupta, P. V. Jallepalli, M. Shih Ie, B. Vogelstein, and C. Lengauer. 2002. The role of chromosomal instability in tumor initiation. Proc Natl Acad Sci U S A 99 (25):16226-31.

Ono, J., G. Auer, T. Caspersson, M. Nasiell, T. Saito, C. Konaka, H. Kato, and Y. Hayata. 1984. Reversibility of 20-methylcholanthrene-induced bronchial cell atypia in dogs. Cancer 54 (6):1030-7.

Padilla-Nash, H. M., K. Hathcock, N. E. McNeil, D. Mack, D. Hoeppner, R. Ravin, T. Knutsen, R. Yonescu, D. Wangsa, K. Dorritie, L. Barenboim, Y. Hu, and T. Ried. 2011. Spontaneous transformation of murine epithelial cells requires the early acquisition of specific chromosomal aneuploidies and genomic imbalances. Genes, chromosomes $\mathcal{E}$ cancer [Epub ahead of print].

Paik, S., S. Shak, G. Tang, C. Kim, J. Baker, M. Cronin, F. L. Baehner, M. G. Walker, D. Watson, T. Park, W. Hiller, E. R. Fisher, D. L. Wickerham, J. Bryant, and N. Wolmark. 2004. A multigene assay to predict recurrence of tamoxifen-treated, node-negative breast cancer. The New England journal of medicine 351 (27):2817-26.

Perou, C. M., T. Sorlie, M. B. Eisen, M. van de Rijn, S. S. Jeffrey, C. A. Rees, J. R. Pollack, D. T. Ross, H. Johnsen, L. A. Akslen, O. Fluge, A. Pergamenschikov, C. Williams, S. X. Zhu, P. E. Lonning, A. L. Borresen-Dale, P. O. Brown, and D. Botstein. 2000. Molecular portraits of human breast tumours. Nature 406 (6797):747-52.

Ried, T. 2009. Homage to Theodor Boveri (1862-1915): Boveri's theory of cancer as a disease of the chromosomes, and the landscape of genomic imbalances in human carcinomas. Environmental and molecular mutagenesis 50 (8):593-601.

Ried, T., K. Heselmeyer-Haddad, H. Blegen, E. Schrock, and G. Auer. 1999. Genomic changes defining the genesis, progression, and malignancy potential in solid human tumors: a phenotype/genotype correlation. Genes, Chromosomes \& Cancer 25 (3):195-204.

Ried, T., K. E. Just, H. Holtgreve-Grez, S. du Manoir, M. R. Speicher, E. Schrock, C. Latham, H. Blegen, A. Zetterberg, T. Cremer, and et al. 1995. Comparative genomic hybridization of formalin-fixed, paraffin-embedded breast tumors reveals different patterns of chromosomal gains and losses in fibroadenomas and diploid and aneuploid carcinomas. Cancer Res 55 (22):5415-23.

Ried, T., R. Knutzen, R. Steinbeck, H. Blegen, E. Schrock, K. Heselmeyer, S. du Manoir, and G. Auer. 1996. Comparative genomic hybridization reveals a specific pattern of 
chromosomal gains and losses during the genesis of colorectal tumors. Genes, Chromosomes \& Cancer 15 (4):234-45.

Rowley, J. D. 1973. Letter: A new consistent chromosomal abnormality in chronic myelogenous leukaemia identified by quinacrine fluorescence and Giemsa staining. Nature 243 (5405):290-3.

Rubin, C. E., R. C. Haggitt, G. C. Burmer, T. A. Brentnall, A. C. Stevens, D. S. Levine, P. J. Dean, M. Kimmey, D. R. Perera, and P. S. Rabinovitch. 1992. DNA aneuploidy in colonic biopsies predicts future development of dysplasia in ulcerative colitis. Gastroenterology 103 (5):1611-20.

Scharf, J. G., and T. Braulke. 2003. The role of the IGF axis in hepatocarcinogenesis. Hormone and metabolic research $=$ Hormon- und Stoffwechselforschung $=$ Hormones et metabolisme 35 (11-12):685-93.

Schlegel, J., G. Stumm, H. Scherthan, T. Bocker, H. Zirngibl, J. Ruschoff, and F. Hofstadter. 1995. Comparative genomic in situ hybridization of colon carcinomas with replication error. Cancer Res 55 (24):6002-5.

Schrock, E., S. du Manoir, T. Veldman, B. Schoell, J. Wienberg, M. A. Ferguson-Smith, Y. Ning, D. H. Ledbetter, I. Bar-Am, D. Soenksen, Y. Garini, and T. Ried. 1996. Multicolor spectral karyotyping of human chromosomes. Science 273 (5274):494-7.

Schulze, S., and I. Petersen. 2011. Gender and ploidy in cancer survival. Cellular oncology 34 (3):199-208.

Shay, J. W., and W. E. Wright. 2002. Telomerase: a target for cancer therapeutics. Cancer Cell 2 (4):257-65.

Sherr, C. J. 1993. Mammalian G1 cyclins. Cell 73 (6):1059-65.

Sinicrope, F. A., R. L. Rego, N. Foster, D. J. Sargent, H. E. Windschitl, L. J. Burgart, T. E. Witzig, and S. N. Thibodeau. 2006. Microsatellite instability accounts for tumor siterelated differences in clinicopathologic variables and prognosis in human colon cancers. The American journal of gastroenterology 101 (12):2818-25.

Sinicrope, F. A., R. L. Rego, K. C. Halling, N. Foster, D. J. Sargent, B. La Plant, A. J. French, J. A. Laurie, R. M. Goldberg, S. N. Thibodeau, and T. E. Witzig. 2006. Prognostic impact of microsatellite instability and DNA ploidy in human colon carcinoma patients. Gastroenterology 131 (3):729-37.

Solinas-Toldo, S., C. Wallrapp, F. Muller-Pillasch, M. Bentz, T. Gress, and P. Lichter. 1996. Mapping of chromosomal imbalances in pancreatic carcinoma by comparative genomic hybridization. Cancer Res 56 (16):3803-7.

Song, J., J. H. Noh, J. H. Lee, J. W. Eun, Y. M. Ahn, S. Y. Kim, S. H. Lee, W. S. Park, N. J. Yoo, J. Y. Lee, and S. W. Nam. 2005. Increased expression of histone deacetylase 2 is found in human gastric cancer. APMIS 113 (4):264-8.

Sorlie, T., C. M. Perou, R. Tibshirani, T. Aas, S. Geisler, H. Johnsen, T. Hastie, M. B. Eisen, M. van de Rijn, S. S. Jeffrey, T. Thorsen, H. Quist, J. C. Matese, P. O. Brown, D. Botstein, P. Eystein Lonning, and A. L. Borresen-Dale. 2001. Gene expression patterns of breast carcinomas distinguish tumor subclasses with clinical implications. Proc Natl Acad Sci U S A 98 (19):10869-74.

Sorlie, T., R. Tibshirani, J. Parker, T. Hastie, J. S. Marron, A. Nobel, S. Deng, H. Johnsen, R. Pesich, S. Geisler, J. Demeter, C. M. Perou, P. E. Lonning, P. O. Brown, A. L. Borresen-Dale, and D. Botstein. 2003. Repeated observation of breast tumor 
subtypes in independent gene expression data sets. Proc Natl Acad Sci U S A 100 (14):8418-23.

Sotiriou, C., S. Y. Neo, L. M. McShane, E. L. Korn, P. M. Long, A. Jazaeri, P. Martiat, S. B. Fox, A. L. Harris, and E. T. Liu. 2003. Breast cancer classification and prognosis based on gene expression profiles from a population-based study. Proc Natl Acad Sci U S A 100 (18):10393-8.

Speicher, M. R., S. Gwyn Ballard, and D. C. Ward. 1996. Karyotyping human chromosomes by combinatorial multi-fluor FISH. Nat Genet 12 (4):368-75.

Spruck, C. H., K. A. Won, and S. I. Reed. 1999. Deregulated cyclin E induces chromosome instability. Nature 401 (6750):297-300.

Strachan, T., and A. P. Read. 1999. In Human Molecular Genetics. New York.

Tjio, J. H., and A. Levan. 1956. The chromosome number of man. Hereditas 42:1-6.

Upender, M. B., J. K. Habermann, L. M. McShane, E. L. Korn, J. C. Barrett, M. J. Difilippantonio, and T. Ried. 2004. Chromosome transfer induced aneuploidy results in complex dysregulation of the cellular transcriptome in immortalized and cancer cells. Cancer Res 64 (19):6941-9.

van 't Veer, L. J., H. Dai, M. J. van de Vijver, Y. D. He, A. A. Hart, M. Mao, H. L. Peterse, K. van der Kooy, M. J. Marton, A. T. Witteveen, G. J. Schreiber, R. M. Kerkhoven, C. Roberts, P. S. Linsley, R. Bernards, and S. H. Friend. 2002. Gene expression profiling predicts clinical outcome of breast cancer. Nature 415 (6871):530-6.

van de Vijver, M. J., Y. D. He, L. J. van't Veer, H. Dai, A. A. Hart, D. W. Voskuil, G. J. Schreiber, J. L. Peterse, C. Roberts, M. J. Marton, M. Parrish, D. Atsma, A. Witteveen, A. Glas, L. Delahaye, T. van der Velde, H. Bartelink, S. Rodenhuis, E. T. Rutgers, S. H. Friend, and R. Bernards. 2002. A gene-expression signature as a predictor of survival in breast cancer. The New England journal of medicine 347 (25):1999-2009.

Vessey, C. J., C. J. Norbury, and I. D. Hickson. 1999. Genetic disorders associated with cancer predisposition and genomic instability. Prog Nucleic Acid Res Mol Biol 63:189221.

Vogelstein, B., and K. W. Kinzler. 2004. Cancer genes and the pathways they control. Nat Med 10 (8):789-99.

Vousden, K. H. 2002. Activation of the p53 tumor suppressor protein. Biochim Biophys Acta 1602 (1):47-59.

Walther, A., R. Houlston, and I. Tomlinson. 2008. Association between chromosomal instability and prognosis in colorectal cancer: a meta-analysis. Gut 57 (7):941-50.

Willenbucher, R. F., S. J. Zelman, L. D. Ferrell, D. H. Moore, 2nd, and F. M. Waldman. 1997. Chromosomal alterations in ulcerative colitis-related neoplastic progression. Gastroenterology 113 (3):791-801.

Yildirim-Assaf, S., A. Coumbos, W. Hopfenmuller, H. D. Foss, H. Stein, and W. Kuhn. 2007. The prognostic significance of determining DNA content in breast cancer by DNA image cytometry: the role of high grade aneuploidy in node negative breast cancer. Journal of clinical pathology 60 (6):649-55.

Zetterberg, A., O. Larsson, and K. G. Wiman. 1995. What is the restriction point? Current opinion in cell biology 7 (6):835-42. 
Zhu, P., E. Martin, J. Mengwasser, P. Schlag, K. P. Janssen, and M. Gottlicher. 2004. Induction of HDAC2 expression upon loss of APC in colorectal tumorigenesis. Cancer Cell 5 (5):455-63.

Zindy, F., E. Lamas, X. Chenivesse, J. Sobczak, J. Wang, D. Fesquet, B. Henglein, and C. Brechot. 1992. Cyclin A is required in S phase in normal epithelial cells. Biochem Biophys Res Commun 182 (3):1144-54. 


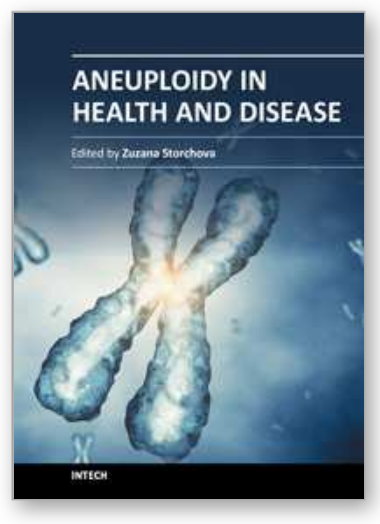

\author{
Aneuploidy in Health and Disease \\ Edited by Dr Zuzana Storchova
}

ISBN 978-953-51-0608-1

Hard cover, 244 pages

Publisher InTech

Published online 16, May, 2012

Published in print edition May, 2012

Aneuploidy means any karyotype that is not euploid, anything that stands outside the norm. Two particular characteristics make the research of aneuploidy challenging. First, it is often hard to distinguish what is a cause and what is a consequence. Secondly, aneuploidy is often associated with a persistent defect in maintenance of genome stability. Thus, working with aneuploid, unstable cells means analyzing an ever changing creature and capturing the features that persist. In the book Aneuploidy in Health and Disease we summarize the recent advances in understanding the causes and consequences of aneuploidy and its link to human pathologies.

\title{
How to reference
}

In order to correctly reference this scholarly work, feel free to copy and paste the following:

Jens K. Habermann, Gert Auer, Madhvi Upender, Timo Gemoll, Hans-Peter Bruch, Hans Jörnvall, Uwe J. Roblick and Thomas Ried (2012). Aneuploidy and Epithelial Cancers: The Impact of Aneuploidy on the Genesis, Progression and Prognosis of Colorectal and Breast Carcinomas, Aneuploidy in Health and Disease, Dr Zuzana Storchova (Ed.), ISBN: 978-953-51-0608-1, InTech, Available from:

http://www.intechopen.com/books/aneuploidy-in-health-and-disease/aneuploidy-and-epithelial-cancers

\section{INTECH}

open science | open minds

\author{
InTech Europe \\ University Campus STeP Ri \\ Slavka Krautzeka 83/A \\ 51000 Rijeka, Croatia \\ Phone: +385 (51) 770447 \\ Fax: +385 (51) 686166 \\ www.intechopen.com
}

\author{
InTech China \\ Unit 405, Office Block, Hotel Equatorial Shanghai \\ No.65, Yan An Road (West), Shanghai, 200040, China \\ 中国上海市延安西路65号上海国际贵都大饭店办公楼405单元 \\ Phone: $+86-21-62489820$ \\ Fax: $+86-21-62489821$
}


(C) 2012 The Author(s). Licensee IntechOpen. This is an open access article distributed under the terms of the Creative Commons Attribution 3.0 License, which permits unrestricted use, distribution, and reproduction in any medium, provided the original work is properly cited. 